\title{
PYLORIC STENOSIS IN OLDER CHILDREN, WITH REPORT OF A CASE OF PYLORIC SPASM ENDING FATALIY
}

\author{
EDWIN E. GRAHAM, A.B., M.D. \\ Professor of Diseases of Children, Jefferson Medical College \\ PHILADELPHIA
}

It is not my intention to study in this paper the condition spoken of as congenital pyloric stenosis in infants, but to consider stenosis of the pylorus in children who have passed the period of infancy. The study of the condition in older children must, however, embrace those patients in whom the condition has persisted from infancy into later childhood, as well as those cases in which infancy has been free from all symptoms of pyloric stenosis, but in which the symptoms appeared months or years later.

At the outset of this study one is immediately impressed by the fact that while medical literature is crowded with articles on congenital hypertrophic pyloric stenosis and pyloric spasm in infants, there has been, as far as I am aware, little written exclusively on the condition in older children.

The discussion in all of these papers deals with the problem as to whether the condition is congenital or not; as to the cause of the hypertrophy of the circular muscular fibers at the pylorus; as to whether in a given case the condition is one of pyloric spasm simply, or hypertrophic stenosis simply, or both spasm and hypertrophy, and as to the necessity for an operation.

The etiology of these congenital or early cases of pyloric stenosis has been considered as due, perhaps, to gastric hyperacidity, or at least to some disturbance of gastric secretion and consequent gastric indigestion. Other causes are hyperplasia at the pylorus, edema of the mucous membrane of the pylorus and pyloric spasm. The causes of spasm are not clear. It may be due to a toxemia, to gastric dilatation, to a change in the gastric secretion, or it may be nervous in origin. The classical symptoms are romiting, constipation, progressive loss in weight, scanty urine, visible peristaltic waves, and possibly finding a tumor at the pylorus.

The treatment ordinarily advised is, feeding, stomach-washing, opium, poultices to epigastrium, saline enematas for the purpose of absorption of liquid, nutrient enemata, operation.

A study of the subject of organic pyloric stenosis as found in American, English, German and French literature has impressed forcibly on me the belief that a careful clinical examination of children and young 
adults will result in bringing to light a fair proportion of cases of organic stenosis during this period of life. The condition was long overlooked in infants; and while not flattering to clinicians, it is, I believe, nevertheless true that the condition is now being overlooked in the older child and young adult.

Children and young adults ${ }^{1}$ who present gastric symptoms that continue for months or years, and especially if vomiting and epigastric pain are present, may be suffering from organic pyloric stenosis, and if such patients have been treated for a long time medicinally without benefit, the probability of there being organic pyloric stenosis increases. Many such cases have finally come to operation, and a pyloric stenosis found by the surgeon at operation.

The reason why medical treatment failed in these patients is then clear. Permanent changes have taken place in the gastric secretory apparatus, the result of the long continuance of the hypertrophic stenosis, and a cure by medical treatment is impossible. An early recognition of the pyloric obstruction should in a fair, or probably in a large, proportion of these cases lead to their cure by medical rather than surgical treatment. This seems at least probable, if one is to reason by the results obtained in pyloric stenosis in infants and older children. A study of the cases in infants and older children treated medically, shows conclusively that the majority of those infants who suffer from a mild degree of hypertrophic pyloric stenosis are cured by the physician and do not come to operation. Heubner ${ }^{2}$ reports nineteen cured in twenty-one infants; Bendix ${ }^{3}$ thirty in thirty-two cases; Hutchison ${ }^{4}$ thirteen in fourteen cases. Stark $^{5}$ eleven out of twelve cases; Bloch ${ }^{6}$ six patients, all recovered.

I do not wish to be understood as implying that there are not patients who require operation. I believe that the position taken on the question of operation by Robert Hutchison," "that operation is never in any circumstances justified in these cases," is an extreme one, but that most of the cases of slight and moderate pyloric stenosis can be cured by medical treatment is my firm belief.

It is an accepted fact that many patients live into advanced adult life, who at autopsy show congenital pyloric stenosis. Rudolph Mayer ${ }^{7}$ reports thirty-one such cases. Cautley and Dent ${ }^{8}$ report three cases of pyloric stenosis at the age of 6,11 and 22 years, respectively, and believe they

1. Maylard: Brit. Med. Jour., July 11, 1908, p. 71.

2. Heubner: Therap. d. Gegenw., 1906, viii.

3. Bendix: Med. Klin., 1909, vi, 1813.

4. Hutchison, Robert: Clin. Jour., Sept. 9, 1008.

5. Stark: Zentralbl. f, Kinderh., 1909, xiv, 5.

6. Bloch: Jahrb. f. Kinderh., 1907, 1xv, 317.

7. Mayer, Rudolph: Virchow's Arch. f. Patl. Anat., 1885, eii, 413.

8. Cautley and Dent: Tr. Roy. Med, and Chir. Soc., 1902, lxxxvi. 
were probably congenital. Mayo Robson reports one case, Lauderer ${ }^{9}$ ten and William Russell ${ }^{10}$ three cases.

There is probably no doubt that congenital pyloric stenosis of a mild grade may remain latent for months and probably for years, and cases of organic pyloric stenosis have been observed during the second and third years of life, where a distinct insufficiency of motility, together with hyperacidity existed. There is probably hardly any year between early infancy and well advanced old age that does not show cases of pyloric stenosis in which the patients have come to operation. Some of these patients have had gastric symptoms from childhood; in others the symptoms vary from a few months to a number of years. Rosenheim ${ }^{12}$ reports a case in a child who had always enjoyed good health until an attack of measles at the age of 5 years, from which he made a good recovery. Three months later the child began to vomit and continued to vomit almost every day. When $61 / 2$ years of age he was operated on and found to be suffering from hypertrophic pyloric stenosis. The case ended in recovery. Osler reports a case of hypertrophic pyloric stenosis in a child that lived until the third year.

There is much room for thought in the study of the cases in which the hypertrophic stenosis is not sufficient in amount to produce dangerous symptoms in infancy. The hypertrophy gradually increases in amount, the stenosis becomes more marked, and in later years the child presents the symptoms directly and indirectly produced by the stenosed pylorus. Beardsley reports a case at the age of 4 years, Sonnenberg one at 5 years, and Hansy one at 11 years (Cautley ${ }^{13}$ ).

Then there are cases that present exactly the opposite picture. The symptoms of hypertrophic pyloric stenosis are very severe in infancy; the babies are so ill that it seems as if they must surely die. They recover, however, and at the age of 3 or 4 years are apparently perfectly well. Robert Hutchison has reported such cases.

The question naturally arises, what has occurred in these cases? Has the congenital hypertrophy of the pylorus largely or partly disappeared? Has the compensatory hypertrophy of the stomach muscles been sufficient to overcome the original condition, and has no gastric dilatation occurred, or has it been a combination of both conditions? Cases are reported in which apparently no gastric dilatation has occurred, and the evidence in such cases points strongly to absorption of the hypertrophy.

What is the explanation of the very large percentage of recoveries reported by certain observers - Heubner, Bendix, Hutchison, Stark, and

9. Lauderer: Tübingen, 1879.

10. Russell, William: Brit. Med. Jour., July 11, 1908.

11. Bernheim (Zurich) : Deutch. med. Wchnschr., 1908, p. 1830.

12. Rosenheim: Berl. klin. Wehnschr., 1899, xxxii, 703.

13. Cautley: Diseases of Children, 1910, p. 264. 
Bloch? I believe it is as follows: Many of these cases are instances of pyloric spasm; others are cases of slight hypertrophic pyloric stenosis; in still others, both spasm and a mild degree of hypertrophy exist, and if one is ready to admit that a slight amount of hypertrophic pyloric stenosis may be largely or in part absorbed, the explanation is quite satisfactory. Stiles, who has operated on many of these patients, claims that true congenital hypertrophic stenosis of the pylorus is rare, and when it does occur, should be treated surgically. Cautley is of about the same opinion, but believes that very mild cases of this disease may recover under medical treatment. Cases of this character may, and probably do, in some instances, show gastric symptoms and evidence of pyloric stenosis in later life, since persistent stenosis in the older child is represented by, first, a period of compensatory stomachic muscular hypertrophy; this is followed by a period which may exist from the inception of the stenosis which represents stagnation and the slow emptying of the stomachic contents; and lastly, retention, or the failure of the stomach ever to completely empty itself. Is it not possible to recognize these cases clinically? Should they come to operation undiagnosed?

The following conclusions in regard to hypertrophic pyloric stenosis in older children and young adults seem to me to be justifiable:

1. Pyloric stenosis is present in children and young adults more commonly than is supposed.

2. The age at which it manifests itself depends on the degree of stenosis present.

3. Pyloric stenosis may be latent for years.

4. It is found by the surgeon during childhood and young adult life, and its early recognition by the physician is important from the standpoint of early medical or, if necessary, surgical treatment.

5. The entire disappearance of all the classical symptoms of congenital hypertrophic stenosis, and the apparent health of the infant during its subsequent early childhood, suggest the probability of an absorption of the hypertrophy, especially as no gastric dilatation may develop later in life.

\section{CASE REPORT}

It may be interesting in this connection to give the history of a case of pyloric spasm in a boy aged $61 / 2$ years, whose general health during infancy and childhood had been first-class until a few months before his death; who presented during the last few months of his life a typical picture of pyloric spasm; who came to autopsy, and in whom no disease of the pylorus or stomach was found post mortem.

History. - W. L., aged $6 \frac{1}{2}$, was admitted to the Jefferson Hospital March 8 , 1911, under the care of Dr. Nassau, and I was asked by Dr. Nassau to see him a few days after his admission. The history of the case was as follows: Mother, father, two sisters, and two brothers were in good health; no hereditary history. 
The child had pertussis one year previously. The left eye was injured by a fall in July, 1909, and the eye was enucleated in November, 1910; he gained 9 pounds in three weeks after the operation. Six weeks previous to admission to Jefferson Hospital he began to vomit. Vomiting occurred at irregular periods, bore no relation to the taking of food, and was most frequent in the morning. Vomiting was preceded by nausea and restlessness, which was relieved by vomiting. Vom. iting might be absent for several days. He had no pain, no blood in the vomitus; had been rapidly losing weight, and was becoming much weaker, and had been confined to bed for one week. There was no history of chills or fever.

- Examination.-The patient was poorly nourished; pupil of right eye was large, but reacted well to light and accommodation; a few submaxillary glands were palpable on both sides; tongue coated, with clean, pink margins. Chest poorly developed; ribs prominent; lungs normal. Abdomen was scaphoid; walls thin; no areas of tenderness or rigidity; no pyloric tumor could be felt. Urine, acid, 1,010 , no albumin, no sugar, no acetone or diacetic acid; urea 2.9 per cent.; few leukocytes; no blood, no casts. March 17, 1911, the child had vomited three times in the previous two days; no vomiting had occurred during the two days previous to that; there was constipation; weight with night elothes and sandals, $35 \%$ pounds. The mother stated that he weighed 57 pounds two and one-half months previously. Report on the vomitus showed no hyperacidity and that bile was present. March 20 a bismuth meal was given. An $x$-ray plate seven hours after the meal showed the bismuth distributed in the stomach, but no trace of bismuth in the duodenum. This plate proved conclusively that food failed to pass normally from the child's stomach in the usual period, as a normal stomach will clear itself of a bismuth meal in from five to seven hours. Another plate showed the gold ball which had been placed in the orbit after enucleation of the eye. I did not learn until afterward that the eye was removed for sarcoma. The stools were small, yellow and well digested. The amount usually vomited at one time was never much more than the amount taken at one feeding. The Morro test was negative.

March 21. The child vomited first Jan. 20, 1910. The vomiting gradually got worse; formerly there was less effort in vomiting, but now vomiting was more violent and retching. He had been constipated all his life. The patient took and retained 14 ounces of water; no tumor was palpable with the stomach so distended. Examination of the unoperated eye showed no lesion of the fundus. The pulse was 130 to 150 ; temperature $97 \mathrm{~F}$. to $102 \mathrm{~F}$. The treatment consisted of liquid nourishment, nutrient enemata, stimulants, bromid of soda and alkalies. As the patient was not improving under medical treatment, and there was evidently from the $x$-ray plates a growth developing in the eye that had been previously operated on, and especially in view of the fact that $I$ had learned that the eye had been operated on for sarcoma, a second operation on the eye was performed by Dr. Howard Hansell March 25, 1911.

Operation on the Eye.-The orbital cavity was completely filled with a dense hard growth, irregular in outline and extending forward to the commissure. The overlying conjunctiva appeared to be healthy. In operating for the removal of the growth, a horizontal incision was made through the conjunctiva from one canthus to the other. Through this opening the finger was introduced and by manipulation the tumor was enucleated and removed in sections. The largest portion included in its center the shrunken sclera, which partly enclosed a gold ball which had been inserted at the time of the enucleation of the globe some months previously.

The floor of the orbit was extensively necrosed and communicated by a large rough-edged, round opening with the antrum of the same side. The floor and outer wall of the orbit were denuded of periosteum, and contained several necrotic areas. The sphenoidal fissure was much larger than normal, by reason of adjacent diseased bone. 
The patient rallied fairly well from the operation, but continued to grow weaker; vomiting continued; the amount of nourishment taken was very small, and he died April 6.

Necropsy.-Post-mortem record of W. L. Date of post-mortem, April 7, 1911, 12 noon.

Pathologic Diagnosis.-Sarcoma of liver, enlarged mesenteric lymph-nodes.

External Examination.-Body is that of an extremely emaciated male child. The left orbit contains a small quantity of gauze, which is saturated with purulent material. Rigor mortis present but easily broken up. Post-mortem suggilla. tion is marked posteriorly.

Internal Examination.-Musculature wasted and subeutaneous fat very scant.

Peritoneum: Smooth and glistening; cavity contains a small amount of clear, straw-colored fluid; liver extends to costal margin, mid-clavicular line. The intestine is partially collapsed; this condition to be described later.

Left Pleura: Free from adhesions; surfaces are smooth and glistening; cavity contains a small amount of straw-colored fluid.

Right Pleura: Resembles its fellow of opposite side.

Pericardium: Smooth and glistening; cavity contains small amount of clear serum.

Heart: Normal in size. Right auricie-ndocardium smooth and glistening; cavity filled with semifluid blood.

Left Ventricle: Wall is $0.6 \mathrm{~cm}$. thick; musculature red and firm; cavity filled with semifluid blood.

Left Lung: Crepitates throughout; cut surface pinkish-red in color, and shows no gross lesions; weight, $160 \mathrm{gm}$.

Right Lung: Same. Weight, $150 \mathrm{gm}$.

Spleen: Measures $6 \times 3 \times 2 \mathrm{~cm}$., is soft and of purplish-red color; weight, $160 \mathrm{gm}$.

Left Kidney: Measures $6 \times 3.5 \times 2.5 \mathrm{~cm}$; red in color; cuts with normal resistance; cortex bears normal relationship to pyramids and is red and injected; capsule strips readily, revealing a smooth surface; weight, $75 \mathrm{gm}$.

Right Kidney: Resembles its fellow; weight, $70 \mathrm{gm}$.

Ureters and Bladder: Show no gross lesions.

Stomach: Contains a small amount of yellowish material; capacity of 175 c.c. The mucous membrane shows some slight post-mortem discoloration. The pyloric orifice is patulous, and the pyloric ring seems to be normal in thickness.

Duodeum: Mucosa bile-tinged, but shows no macroscopic lesions.

Liver: Normal in size, reddish color, capsule smooth, cuts with normal resistance. In the right lobe near the anterior margin there is a firm, yellowish nodule measuring $4 \mathrm{~cm}$. in diameter, sharply demarcated from the surrounding liver tissue. Remainder of organ apparently normal.

Pancreas: Normal in size and color, and shows no noteworthy lesions.

Intestines: Mesenteric lymph-nodes are enlarged, firm and of reddish color. The small intestine at a distance of $20 \mathrm{~cm}$. from the ileocecal junction is collapsed for a distance of about $50 \mathrm{~cm}$. Remainder of organ shows no lesions.

Vena Cava and Aorta: Normal.

Microscopic Diagnosis.-Tumor of Liver: Small round-celled sarcoma.

Pylorus: Normal.

Mesenteric Glands : Hyperplasia of lymphoid tissue.

Brain: Showed nothing.

The case of pyloric spasm here reported and coming to autopsy is to me of great interest. It was unconnected with any organic disease of the stomach, or with any change in the normal gastric secretion. Spasm of the pylorus in older children is spoken of by many authors, and is usually described as being associated with severe pain, perhaps 
little or no vomiting, and often connected with disease of the pancreas, appendix or gall-bladder, gastric ulcer, or distinct change in the gastric secretions. Pain was absent in my case; romiting was the one prominent symptom, and loss in weight was rapid and extreme. In these two particulars, absence of pain and violent and persistent vomiting, it differs from the cases described by most writers. After the enucleation of the eye, the vomiting lessened, and in three weeks the boy gained 9 pounds. The vomiting ceased for five or six weeks after the first operation, and then gradually increased in frequency and severity until the second operation, when the sarcomatous mass was thoroughly removed from the orbit.

The case appears to belong to the group of so-called nervous vomiting; of reflex origin, associated primarily with disease of the eye, and later, aggravated by metastasis in the liver. Reflex vomiting of eye origin is independent of the taking of food, and while it lasts is persisient. The romiting of eye origin does not last for days, and is usually followed by an ability to take and retain food. The primary operation was followed by entire cessation of romiting, and a gain in weight. The sarcoma returned in the orbit, metastasis occurred in the liver and both these conditions caused, in my opinion, a severe return of this gastro-neurosis. The operation of cleaning out the orbit only slightly affected the vomiting; the boy was in a deplorably weak condition at the time of the operation, and the sarcoma of the liver was probably instrumental in causing a continuance of the vomiting, which persisted, although in a less degree, until his death. In my opinion, the second operation neither hastened or retarded death.

The stomach through the srmpathetic and cerebrospinal nerves is connccted with practically all organs and tissues in the lumman body, and it has been demonstrated that pyloric spasm can be produced artificially by stimulation of the vagus. 'The contraction of involuntary muscular tissue, the source of the contraction being outside the stomach, is at least probable.

Is pyloric spasm unassociated with pain and with persistent romiting. a common condition, or even an occasional condition in older children? It certainly clinically does not resemble the cases described as associated with gastric ulcer, ${ }^{14}$ and gall-stone colic in which the pain is excessive and vomiting not a marked symptom. Periodic pyloric spasm may oceur at the menstrual period, ${ }^{15}$ unassociated with any disease of the stomach, or with spasm in any other portion of the body, and under such conditions is probably a primary spasm of the pylorus, a motor neurosis. Lauder Brunton's observations tend to show that pyloric spasm may accompany migraine, and be a manifestation of a neurosis.

14. Fairchilds: Iowa Med. Jour., Des Moines, 1910-1I, xvii, 212.

15. Hemmeter: Diseases of the Stomach, Ed: 3, p. 744. 
A number of cases of infantile pyloric spasm have been followed up to the age of 5 years and older, and found to be in first-class health, and a neurotic family history is not found in quite a considerable number of such cases. The clinician should not lose interest in these babies after they pass beyond the period of infancy, and an effort should be made to follow their subsequent histories, especially with reference to any gastric symptoms.

Cases of infantile pyloric spasm have been kept under observation for years. $^{17}$ All the symptoms may persist until the third year, and the child may remain nervous and anemic for years afterward. In other cases, solid food cannot be given until the child is 3 or even 5 years old. In still other cases of spasm, romiting may persist until the child is 4 years old or older, and the peristaltic waves may continue until the child is over 4 years of age.

Cases diagnosed as cyclic vomiting have come to autopsy ${ }^{18}$ and the lumen of the pylorus has been found to be very small, with a distinct hrpertrophy. In these cases the children may be 4 or 5 years of age, the symptoms of epigastric pain and vomiting having been present since birth, returning at irregular intervals of months, and the children being apparently perfectly well between the attacks.

I do not mean to give the impression that cyclic romiting and prioric spasm are not two entirely different conditions, but to suggest the advisability of considering the possibility of pyloric spasm producing s!mptoms that resemble closely those of cyclic romiting.

What are the causes of the pylorospasm in infancy that disappears in later childhood? Half of these children are breast-fed, and it seems to me unnatural to claim, as does von Starck. that the unaccustomed presence of food in the stomach produces an irritation of the gastrie mucosa and so rauses the spasm.

A clearer understanding of the etiology in infants may help us in the recognition and study of the condition in older children.

1713 Spruce Street.

16. Von Stark: Zentralbl. f. Kinderh., May 1, 1909.

17. Heubner: Berlin, Therap. d. Gegenw., 1906, viii, 433.

18. Russell: Proc. Roy. Soc. Med., Iondon, 1909-10, iii, Sect. Dis. Child., 78. 